\title{
Inequality and Happiness
}

\author{
Ada Ferrer-i-Carbonell \\ IAE (CSIC), Barcelona GSE, \& IZA \\ $\&$ \\ Xavier Ramos \\ Universitat Autònoma de Barcelona, IZA \& EQUALITAS
}

September 2, 2013

\begin{abstract}
In recent years there has been an accumulation of empirical evidence suggesting that individuals dislike inequality (Alesina and Giuliano, 20II and Dawes et al., 2007). The literature has built upon estimating the degree of this dislike as well as its causes. The use of self-reported measures of satisfaction or well-being as a proxy for utility has been one of the empirical strategies used to this end. In this survey we review the papers that estimate or examine the relationship between inequality and self-reported happiness to conclude that inequality correlates negatively with happiness in Western societies. Some of the surveyed papers identify particular sources of heterogeneity on preferences over inequality. The evidence for non-Western societies is more mixed and less reliable. Notwithstanding that, trust in the institutions seems to play an important role in shaping the relationship between income inequality and subjective wellbeing. We conclude with suggestions for further research.
\end{abstract}

Keywords: inequality, happiness, inequality aversion. 


\section{INTRODUCTION}

There are many reasons to believe that individuals dislike inequality. Importantly, individuals may have a genuine distaste for inequality (Dawes et al., 2007). Fairness concerns about the nature and processes that lead to perceived or observed disparities may also explain dislike for inequality. Individuals may also dislike it if they (believe that they) could be better off in a more equal situation (Piketty, 1995; Bénabou and Ok, 200I).

Such prior about the possible relationship between inequality and happiness or life satisfaction, however, has not been tested directly for representative samples until recently, with the use of self-reported subjective well-being questions included in large-scale surveys. In this literature survey we review the papers that estimate or examine the relationship between inequality and self-reported happiness. Other than the use of subjective measures, lab experiments are the most prominent way to analyze inequality aversion for small groups of not necessarily representative individuals (see Senik, 2009 for a survey).

There is also a large literature on preferences for redistribution, which is certainly related to individuals' dislike for inequality. However, the preference individuals have for redistribution is not solely determined by their dislike for inequality. Other factors, such as trust, the efficacy of the state, or corruption do play an important role in shaping individuals' preferences for redistribution (Algan, Cahuc, Sangnier 20II; Di Tella and MacCulloch 2009; Alesina and Angeletos 2005). Thus in this overview we will refrain from using preferences for equality and preferences for redistribution as perfect substitutes and will not delve into that literature. That is, the relationship between inequality and happiness captures preferences for equality or inequality aversion, but do not measure the related and much studied concept of preferences for redistribution.'

The paper is structured as follows. Section 2 briefly discusses the main methodological issues related to the two key variables: the use of subjective measures as a proxy for utility, on the one hand, and the measurement of inequality, on the other hand. Section 3 sketches the main pathways that explain why inequality is expected to affect 
individual wellbeing. Section 4 reviews the empirical findings, pointing out the strengths and weaknesses of the empirical studies. Finally, section 5 provides some concluding remarks and raises points for future research.

\section{EMPIRICAL APPROACH TO HAPPINESS \& INEQUALITY}

\section{I Measuring happiness: Subjective well-being}

The literature surveyed in this paper uses subjective questions on well-being, also called happiness or life satisfaction, to proxy individuals' utility and to estimate the relationship between inequality and individuals' well-being. With subjective questions on well-being, individuals are asked about where on a scale of, e.g., 0 to 10, they are in terms of life satisfaction or happiness. As an example, we quote the satisfaction question posed to respondents of the German Socio Economic Panel (SOEP):

In conclusion, we would like to ask you about your satisfaction with your life in general. Please answer according to the following scale: 0 means "completely dissatisfied", 10 means “completely satisfied". How satisfied are you with your life, all things considered?

Using the responses to this or similar subjective well-being questions, researchers have examined the relationship between reported happiness and individuals' circumstances, such as own income or income of the others, occupational status, family situation, health, inflation, unemployment rate or, as the focus of this survey, inequality in the region where the individual lives.

In order to use the answer to the happiness question as a proxy measure of utility, two main assumptions have to be imposed: (I) Individuals are able and willing to provide a meaningful answer that is a positive monotonic transformation of the theoretical underlying concept we are interested in, i.e. utility; and (2) individuals' answers to the satisfaction questions can be compared in a meaningful way. This means that the answers to the subjective satisfaction question are interpersonal comparable either at the ordinal or cardinal level. 
The empirical evidence supporting these two assumptions is ample and comes from various disciplines. First, there is large empirical evidence showing a consistent correlation between the answer to the happiness questions and some objective measure of happiness, such as the amount of smiling or changes in facial muscles during the questionnaire interview (Sandvik, Diener and Seidlitz, 1993; Kahneman, 1999), objective measures of health (Blanchflower and Oswald, 2008 and Steptoe and Wardle, 2005), and physical measures of brain activity (Urry et al., 2004). Second, there is an emerging string of literature that links individuals' behaviour to their reported happiness level. If individuals behave so as to "maximize" their utility and self-reported happiness is a good proxy for utility, happiness reports should correlate with behaviour. This literature, although yet starting, does find evidence indicating that individuals stop carrying activities that yield low satisfaction levels. Clark (200I) reports that job satisfaction can predict future job quits, and Guven, Senik, and Stichnoth (2010) find that the satisfaction gap between spouses explains the probability of future divorce. In short, there is now large evidence on the reliability of subjective well-being measures to be confident that we can measure individuals' well-being in a meaningful way (see Clark, Frijters, and Shields, 2008; Ferrer-i-Carbonell, 20II and 2012; Frey and Stutzer, 2002; Layard, 2010; Powdthavee, 201 I; and Van Praag and Ferrer-i-Carbonell, 2004 for surveys). There is also empirical evidence supporting the existence of a unique shared concept of happiness. Notably, individuals are fairly good at predicting other individuals' life satisfaction by looking at videos or even at pictures (Diener and Lucas, 1999; Sandvik, Diener and Seidlitz, 1993). Although the empirical evidence indicates that individuals share a similar concept of happiness or well-being, individual interpersonal welfare comparisons remain a debatable issue. Therefore, while the use of subjective questions to learn about the determinants of happiness and to gain new insights on individuals' preferences is widely accepted, using satisfaction questions to make welfare judgments is often criticized. The research surveyed in this paper refers to the first line of research only.

\subsection{Estimating taste for inequality: Empirical approach}

The empirical approach used in the literature is based on estimating a happiness function that looks like 


$$
H_{i t}=\alpha+\delta_{1} T+\delta_{2} R+\gamma X_{i t}+\beta_{1} I_{r t}+\beta_{2} I_{r t} Z_{i t}+\beta_{3} Z_{i t}+\eta_{i}+\varepsilon_{i t}
$$

where $i$ indicates the individual and $t$ the time. The happiness equation usually includes regional $(R)$ and time $(T)$ fixed effects. These fixed effects capture all those unobservable variables that are time or region specific, such as the macro-economic situation of each specific region and year or institutional characteristics of each region. The main variables of interests are usually a set of individual characteristics $X$, such as health, age, income, income of the others, occupational status, and family situation.

In the specific case of inequality, the regression analysis includes an inequality measure (I) so as to estimate its impact on happiness. If the data used is panel, inequality can change across time and region. Otherwise, only regional differences can be exploited in the empirical analysis. Some of the studies discussed in this survey examine some type of heterogeneity on inequality aversion. That is, they empirically estimate whether inequality aversion is similar across population groups or if instead, it differs depending on, for example, individuals' place of residence $(R)$ or on individual characteristics such as income or gender. In this case, a common approach is to interact the inequality measure $I$ with the variable describing the dimension generating heterogeneity $(Z)$.

The use of panel data in the empirical analysis of a happiness equation is crucial, as it allows the researcher to control for those individual unobservable characteristics that are constant over time, such as optimism, intelligence, or capacity to deal with adversities. Ferrer-i-Carbonell and Frijters (2004) show that including this time constant individual fixed effect $\left(\eta_{i}\right)$ can considerably change the estimated coefficients. Therefore, its exclusion biases the results. Finally, the equation includes the usual error term $\left(\varepsilon_{i t}\right)$. Inequality is usually estimated at the regional level, so one ought to use cluster standard errors. However, most of the empirical analyses have too few clusters (regions) and clustering may thus lead to biased estimates (Angrist and Pischke, 2009; Cameron and Miller, 2010; Wooldrige, 2006). Therefore, the empirical literature typically does not cluster by region, which means that the coefficients are unbiased but statistical inference may be jeopardized. 
The econometric method used to estimate the happiness equation largely depends on whether the researcher assumes cardinal or ordinal happiness. If happiness is assumed to be ordinal, the difference between happiness answers does not have a particular meaning, even though all individuals interpret happiness in a similar manner. Although the distinction between cardinality and ordinality is very important from a theoretical perspective, the empirical literature has shown that there is virtually no difference between estimating the happiness equation by means of a linear or an ordered categorical estimator (Ferrer-i-Carbonell and Frijters, 2004). ${ }^{2}$ This means that the results presented in the survey can be easily compared among themselves regardless of whether they assume cardinal or ordinal happiness. Comparison among papers, however, will be hampered depending on whether they employ or not panel data.

\subsection{Measuring Inequality and choosing the relevant population subgroup}

In the empirical literature we are reviewing, inequality is (with very few exceptions) measured by the gini coefficient in the region or country where the individual lives. This literature has so far not addressed two important issues related to the measure of inequality employed in the empirical analysis. First, the literature has not examined the robustness of the results to the different ways of measuring income inequality. Since different inequality measures incorporate different value judgements about the relevance of transfers at different locations of the income distribution, a robustness analysis would help us understand what type of inequality individuals are more sensitive to.

Second, it has not analysed the relevance of the population subgroup over which inequality is measured. That is, the literature has not yet examined the appealing distinction between "within" and "between" group inequalities. It may well be that individuals have different taste for inequality when judging individuals of the same reference group ("within inequality") than when examining the society in general. The within inequality may be related to individuals relative concerns, this is, the fact that individuals are negatively affected by the income of their reference group. The subjective literature has found that the richer the individuals' reference group is, the unhappier individuals are. The effect of the between inequality however has not been studied and we can only survey the results of overall inequality on happiness. The 
between and within group inequality effect could differ if, for example, the weight that individuals assign to effort or to luck as determinants of income in a society differs depending on whether they judge individuals from the same group or not. As a matter of example, suppose that reference groups are defined by education attainment and age, and individuals believe that education disparities are mostly due to factors that are beyond individual's responsibility, say the family they are born into, but income differences of individuals with similar education and age are mostly due to effort. We should then find a negative coefficient of between inequality on happiness and a nil effect of within inequality. This would also be consistent (and even reconcile) the two findings in the happiness literature: a negative effect of overall inequality and a positive effect of being at the top of the income distribution of own reference group.

\section{WHY AND HOW DOES INEQUALITY AFFECT HAPPINESS?}

Several arguments explain the possible effect of income inequality on happiness. A first set of arguments is grounded on the self-interest of individuals. People (dis)like inequality because they perceive there is a positive probability that they could benefit (loose out) from it. A second view defends that the inequality (dis)like may also be due to individuals genuinely caring for their fellow citizens, beyond the implications that inequality may directly have on their well-being. That is, individuals have certain social preferences, for example related to fairness, and these shape their taste for equality. Finally, we also examine the role that relative concerns have in determining the direction of the effect of inequality on happiness. Next we outline these pathways.

\section{I Self-interest}

Individuals' dislike for inequality is partly explained by self-interest motives. Depending on their characteristics and circumstances (e.g. growing up in recession, experiencing a radical political or economic transition), individuals associate the inequality of the income distribution with worse or riskier future outcomes or instead with greater opportunities, and this is what shapes their attitude to inequality. Linking inequality with worse outcomes leads to low tolerance for inequality, whereas relating it to enhanced opportunities leads to accepting inequality more easily. 
Inequality is bad for me, so I do not like it: As long as people view the income distribution as indicative of the distribution of outcomes they face in case of a shock, they may dislike the probability of falling into a worse situation and thus dislike inequality. This would imply that more risk averse individuals will also be more inequality averse, as Ferrer-i-Carbonell and Ramos (2009) show. In this scenario, the attitudes toward inequality are also influenced by the history of individuals. A history of misfortune may exacerbate individuals' risk aversion, make them pessimistic about their prospects of upward mobility, and so more inequality averse (Piketty, 1995; Giuliano and Spilimbergo, 2009). Similarly, income mobility prospects also matter. Individuals expecting to fall down the income ladder will prefer a more equal rather than more unequal distribution (Bénabou and Ok, 200I).

The dislike for inequality may also be instrumental if individuals believe that some features of society, which negatively affect their well-being, are brought about by inequality. Criminal activity is perhaps the first example that comes to mind. We expect those who are more likely to be victims of criminal activities to have a stronger dislike for inequality, ceteris paribus. Note that such a dislike does not come from a genuine disapproval of inequality, but from the indirect effect of inequality on crime (i.e. a willingness to improve their well-being through a reduction in crime).

Inequality is good for me, so I do like it: People who have little or nothing to loose from an economic shock should like inequality, since it signals the possibility of better outcomes if a shock occurs. ${ }^{3}$ This effect may be attenuated by large loss aversion. Similarly, those with prospects of upward mobility should also be related to larger tolerance for inequality. Individuals who expect to move up the income ladder have better prospects in more unequal distributions and thus will approve of inequality. At an aggregate level, societies experiencing rapid development may initially show tolerance for large inequalities, as this implies better opportunities. However, as good expectations are not realized, such tolerance may turn into dislike (Hirschman and Rothschild, 1973; Grosfeld and Senik, 2010). 


\subsection{Regard for others}

There is by now sufficient (mostly experimental) evidence that shows that individuals not only care about themselves but also care about others. A growing body of literature argues that humans are influenced by truly egalitarian preferences (Bergstrom and Lachmann, 1998; Fehr and Schmidt, 1999) and that individuals are happier in more equal environments (Dawes et al., 2007).

Fairness concerns and beliefs are also important. Individuals do not only care about outcomes, but also about how they came about, that is about the fairness of the processes that led to those outcomes. Above and beyond the satisfaction that people directly derive from processes being fair (i.e. procedural utility, Frey, Benz and Stutzer, 2004), their judgment of an outcome tends to be better when the process is perceived as fair. This means that preferences for equality also depend on the individual perceptions about the fairness of the income generating processes. Individuals show higher tolerance for inequality when economic advantage is believed to be more related to individual effort rather than to other elements that people think ought to be unrelated to economic advantage, such as birth, nepotism, luck or corruption. (Alesina, Di Tella and MacCulloch, 2004). Moreover, the interplay of such beliefs and welfare policies lead to multiple equilibria, where those beliefs are self-fulfilled. For instance, in a society where effort is believed to be the main determinant of income, redistribution and taxation will be limited, effort will be high, the role of luck will be reduced and social beliefs will be self-fulfilled (Alesina and Angeletos, 2005).

The income inequality coefficient reviewed in this paper captures the relationship between actual inequality and self-reported happiness. However, individual tolerance for inequality depends not on the objectively measured inequality but on the perception about the extent of income inequality. If perceptions are not accurate and the error is unbiased, the estimated coefficient will usually be an underestimate of the true coefficient. This is known as attenuation bias or the iron law of econometrics (Hausman, 200I). However if the erroneous perceptions correlate with individual characteristics, then the coefficient will not only be biased but the direction of the bias will be unknown. ${ }^{4}$ 


\subsection{Relative concerns: the income comparison effect}

The subjective happiness literature has empirically tested the importance of relative concerns and almost unequivocally concludes that individuals' position in the income distribution of their reference group affects happiness. If individuals get happier from being ranked higher in the income distribution of their reference group and vice versa, then it is not straightforward to predict the effect of inequality on happiness. Individuals at the top of the income distribution should like (within) inequality to the extent that they experience a positive comparison effect. There are two main arguments on why relative concerns (that is, the importance of the income of the reference group for own happiness) may not be in contradiction with the dislike for inequality.

First, relative concerns seem to be asymmetric and this could explain the negative effect of inequality on happiness or utility. Fehr and Schmidt (1999) distinguish between upward comparisons, to those having more, and downward comparisons, to those having less. If in their model individuals have envy (dislike for others having more) and compassion for those having less, then individuals will have higher utility in more equal societies. This is so even when one's own income level is kept constant. The empirical evidence suggests that relative concerns may indeed be asymmetric. That is, individuals get unhappier from being poorer than their reference group but are not affected from being richer (Ferrer-i-Carbonell, 2005). Were this empirical finding corroborated, it would be consistent with inequality dislike (Hopkins, 2008).

Second, and as discussed above, this literature has not distinguished between from within inequality. If individuals have different preferences over those perceived as equals (within inequality) and those perceived as not equals (between inequality), the income distribution of each group will also have a different impact on happiness. We are not aware of any study that has empirically examined this issue. The existing literature has only examined the effect of overall inequality on happiness.

Relative concerns may also translate into positional consumption, which in turn affects happiness through the negative externalities it generates. The relationship between inequality and positional consumption is however not obvious. A simple model of 
conspicuous consumption rivalry to maintain one's apparent relative position, predicts a positive effect of inequality on happiness, as more equality (i.e. denser distribution) increases competition for ranks, which leads to higher conspicuous consumption and lowers utility (Hopkins, 2008). That is, positional externalities are larger in more equal societies in which there is more competition for conspicuous consumption. There are arguments however that run in the opposite direction. Frank (2013) claims that the increase of top earners in the US (we add: together with social transparency) has led to an increase of positional consumption and externalities. That is, the inequality increase experienced in recent years has increased positional externalities and thus decreased happiness (Frank, 2013). He argues that increasing consumption of top incomes in the US have had a trickledown effect on conspicuous consumption of individuals in the lower positions of the income distribution. Bowles and Park (2005) use ten OECD countries (1963-1998) and find empirical evidence of a positive relationship between inequality and number of working hours, which may, everything else equal, also decrease happiness.

In short, although not obvious, positional concerns may be reconciled with inequality aversion despite simpler models would indicate the contrary.

\section{EMPIRICAL EVIDENCE}

\section{I. Western countries}

The empirical evidence has shown that inequality, usually measured by the gini coefficient in the region or country where the individual lives, has a negative coefficient on self-reported well-being or life satisfaction in most western countries, but not in all. This means that other things being equal individuals in more unequal societies report on average a lower score on the satisfaction scale. Thus, even though inequality may also have positive effects on happiness, the aggregated impact is usually estimated to be negative. Examining the importance of inequality for happiness implies understanding that happiness depends not only on individuals' own situation but also on that of their fellow citizens. For example, it has been shown in the literature that the economic situation of others (reference group) and how well individuals perform in comparison (relative) to this reference group has a clear impact on own happiness (Ferrer-i-Carbonell, 2005 and Luttmer, 2005). In here we will focus exclusively on the 
papers that have estimated the importance of regional income distribution on happiness.

One of the first studies using subjective measures to examine inequality aversion is Morawetz et al. (1977). The authors compare the self-rated happiness of two small Israeli communities that were similar in (almost) all respects except for their income distribution and conclude that individuals living in the most egalitarian village (Isos) were happier than those living in the less egalitarian village (Anisos). An early study by Van Praag, Hagenaars, and Van Weeren (1982), using individuals' evaluation of hypothetical incomes (a measure similar to financial satisfaction), also show the importance of country income inequality.

The use of subjective measures included in large representative samples to study inequality aversion started very recently. Alesina, Di Tella and MacCulloch (2004) find that while European respondents' life satisfaction is negatively correlated with inequality, such correlation is not found for American respondents in general. Dislike for inequality is also found to relate to their wealth and political preference (leftist and rightist). While for Americans, political preferences do not matter, they do for Europeans, where the negative correlation between inequality and happiness is driven exclusively by the inequality aversion of leftist preferences. The analysis by income level reveals that inequality aversion is a 'luxury good' for Americans. That is, the richer (top half of the income distribution) are inequality averse while the poor are unaffected by inequality. For Europe they find the opposite results. The authors argue that these country differences are likely to be due to US citizens believing that they live in a highly mobile society. If individuals perceive that they live in a mobile society where effort is an important determinant of income, income inequality may be perceived as fairer and individuals may not dislike inequality, as it is the case for most Americans. Alesina and Angeletos (2005) report that there is a widespread believe amongst Americans that effort, as opposed to luck, birth or connections, is the main determinant of economic advantage. In addition, if Americans believe that they indeed live in a mobile society, poor individuals can only gain from inequality while rich individuals can only loose by moving down the economic ladder. This is one possible explanation why in America rich individuals dislike inequality while the poor do not. 
The authors defend their argument by pointing to the fact that according to the World Values Survey, 7I\% of Americans believe that the poor have a chance of escaping from poverty, while in Europe this figure is only $40 \%$. There are other explanations that one can think of, although the authors do not exploit them. Under the premise that US citizens might perceive that current inequality is the outcome of a fair process, and to the extent that inequality may be related to crime and other bads, equality might be a luxury good that only the richest can afford. Another explanation might be related to knowledge. If income and education are correlated, individuals at the bottom of the income distribution may lack the education and knowledge to understand inequality. In other words, the poor may be too poor to be aware of the income distribution of their region and therefore might not be affected by it.

Blanchflower and Oswald (2003) use the General Social Survey (1976 to 1996) and find that earnings inequality measured at the US state level has a negative but small effect on happiness. These results are not entirely consistent with the ones discussed above. It is important to notice that the coefficient estimates in Blanchflower and Oswald (2003) are very small in magnitude and that these authors use earnings, and not income, inequality. The inequality aversion found in their study is completely driven by workers (as opposed to non-workers), individuals under 30 , and those with low education levels (less than 13 years of education), which is also at odds with Alesina, Di Tella and MacCulloch (2004) findings that only individuals with higher education levels are inequality averse. The inequality measure used by Blanchflower and Oswald (2003) is not the gini coefficient but the ratio of the mean of the $5^{\text {th }}$ earnings quintile to the mean of the $\mathrm{I}^{\text {st }}$, which is a very unsatisfactory measure as it ignores what happens in the middle of the distribution. It would therefore be interesting to know to what extent the different measures of income (earnings versus total income) and of inequality are responsible for the differing results found between the two US studies.

In Germany, Schwarze and Harpfer (2007) and Ferrer-i-Carbonell and Ramos (2009) find a clear negative impact of inequality on self-reported life satisfaction using various waves of the German SOEP. These two studies use the gini coefficient and are consistent with the results in Alesina, Di Tella and MacCulloch (2004), who found 
Europeans to be inequality averse. Ferrer-i-Carbonell and Ramos (2009) test one of the hypotheses to explain the dislike for income inequality by examining whether the estimated inequality aversion depends on individual risk attitudes. Their empirical findings indicate that inequality and risk aversion are strongly correlated: more risk averse individuals are also more inequality averse, and vice versa. The estimated relationship between risk attitudes and inequality aversion survives the inclusion of individual characteristics (i.e. income, education, and gender) that may be correlated with both risk attitudes and inequality aversion.

While the above studies have empirically found a negative association between inequality and happiness, other studies have found the opposite effect. It is important to mention however that all these studies have a very specific approach and some suffer from empirical limitations. Clark (2003) uses only full time employed respondents of the BHPS and finds a positive correlation between individuals' wellbeing and the reference group income inequality. This contrast with the other studies in the literature in two aspects: (i) the sample selection; and, most importantly, (ii) the fact that it does not look at the (overall) inequality in the region but at the inequality among a very specific group of individuals with whom the respondent "competes". In other words, it estimates the effect of the within group inequality on happiness. Therefore, and in line with the literature on relative concerns, it is not surprising that Clark finds a positive coefficient. This finding could be consistent with the idea sketched above that individuals may like within group inequality but dislike (or be indifferent to) between group inequality, an idea that has not been empirically tested as yet. The sum of the two effects may lead to the often found negative (overall) inequality effect on happiness.

Tomes (1986) finds mixed evidence for Canada. This study suffers from an important data limitation, i.e. the author uses cross-section data and therefore, and in contrast with all evidence mentioned above, he cannot control for individual time persistent effects. The subjective well-being literature has highlighted the sensitivity of the results to the introduction or not of those individual effects (Ferrer-i-Carbonell and Frijters, 2004). In contrast with the rest of the literature, this study also uses a very coarse and 
unsatisfactory measure of inequality, i.e. the income shares of the bottom $40 \%$ and top $10 \%$ of individuals.

In another study, Sanfey and Teksoz (2007) use data from the World Values survey and find that the coefficient of income inequality, measured by the gini coefficient on happiness, is negative for individuals in transition countries and positive for the nontransition ones. The empirical exercise however has an important limitation: the regression analysis does not include either country nor time fixed effects. This means that the variables included in the regression (i.e. Gini, GDP, unemployment, and inflation) are absorbing the effect of those not included (e.g., crime, social cohesion, health, tax system, public expenditures or degree of urbanization) that are correlated with the included ones. This means that the coefficient of the gini index might be capturing other country characteristics that correlated positively with the gini.

\subsection{Non-Western Countries}

Next, we will survey the empirical literature for non-Western countries. An important limitation of all these studies is that they do not use panel data, which as argued above, will most likely yield biased estimates (Ferrer-i-Carbonell and Frijters, 2004). At most, researchers have repeated cross-section data, which allows them to exploit the changes over time of inequality aversion.

Graham and Felton (2005) use cross-sectional data for 17 Latin American countries included in the latinobarómetro mostly from the 2004 wave. These authors exploit the large cross-country variation in income inequality to estimate, among other things, the importance of inequality, measured by the gini coefficient, for happiness in a rather coarse manner. They classify the countries into three groups, according to their gini coefficient: low $(<=0.5)$, medium $((0.5,0.55])$, and high $(>0.55)$ inequality, and find a non monotonous relationship. The unhappiest individuals are found in high inequality countries, those in low inequality countries follow them, while the happiest individuals are those in medium inequality countries. The authors do not provide any explanation for this finding and we cannot relate their results to any of the theoretical arguments on why individuals may like or dislike inequality. An interesting contribution made by this study is the inclusion of education inequality (measured by the Theil index) into 
the analysis. The empirical analysis suggests that individuals in high education inequality countries are the happiest. As the authors acknowledge, besides not being able to control for individual fixed effects, their analysis suffers from another limitation: their approach of grouping the countries in three categories according to their level of income or education inequality (low, medium, and high). With this grouping, the authors cannot exclude the possibility that the countries in each group have something else in common than only their inequality levels. It could well be that it is those common characteristics within the group what makes individuals in those countries happier and unhappier, rather than inequality itself.

The evidence in transition countries is still limited and very challenging. Grosfeld and Senik (2010) find that Poles were rather tolerant towards inequality until 1996, when their dislike for inequality started to increase. The authors suggest that the year break (1996/1997) corresponds with an increasing mistrust in the political system and elites, which would explain the change in (dis)taste for inequality. The authors defend that the inequality at the beginning of the transition period was seen as a sign for increasing opportunities, whereas after a while people became more sceptical about the legitimacy of sustained inequality. Again, these findings suggest that the acceptance of inequality seems to depend on how individuals perceive its legitimacy.

Sanfey and Teksoz (2007) use data from the World Values survey (1999-2002) and find that individuals in higher income inequality (measured by the gini coefficient) transition countries report lower levels of satisfaction. That is, individuals in transition countries are inequality averse. Since the data used in Sanfey and Teksoz (2007) is from 1999. 2002, which is after the 1996/1997 break (arguably transition countries will have the break in similar years), this results are consistent with those of Grosfeld and Senik (2010). As already mentioned in section 4.I, this empirical exercise suffers from an important limitation, that is, it does not include either country nor time fixed effects. This means that the gini coefficient could be capturing other country characteristics correlated with both, the gini and happiness. 
All in all we can conclude that the fast changing, volatile, and particular situation of those economies in transition hampers obtaining general conclusions about individual preferences.

\section{CONCLUDING REMARKS}

A growing amount of empirical research finds that most individuals dislike inequality. The increasing availability of self-reported satisfaction measures in nationally representative surveys has allowed empirically investigating in a simple and direct way whether inequality matters for individual welfare for an increasing number of countries in different macroeconomic and socio-political conditions. We have reviewed the empirical literature that employs such self-reported satisfaction or well-being as a proxy for utility to examining individuals' dislike or aversion to income inequality.

We distinguish between the evidence for Western and for non-Western countries. In Western societies, the studies that employ reasonable inequality measures and control for individual time-invariant effects, find that income inequality has a negative effect on individual wellbeing. Further work, however, is necessary to identify and understand the nature and origins of such a negative relationship between inequality and happiness. Ferrer-i-Carbonell and Ramos (2009) provide evidence about the mediating role of risk aversion, while Alesina, Di Tella and MacCulloch (2004) conjecture about the importance of mobility beliefs to explain the different attitudes to inequality of Americans and Europeans.

The evidence for non-Western countries is mixed and, most importantly, less reliable since there is usually no longitudinal data available, so individual fixed effects cannot be controlled for, which results in biased estimates. In addition, some of the studies do not control for country fixed effects, which implies that the gini coefficient may be capturing other macro variables (such as, social conditions, tax system, and public expenditures) correlated with both, happiness and gini. The scarce evidence available for countries in transition provides an interesting story, where trust in the institutions of the country seems to shape individuals' attitudes towards inequality. 
Most studies use overall (regional) income inequality. We have argued that there are grounds to believe that income differences which occur among individuals deemed as relevant 'equals' is likely to exert a different effect on individual well-being than differences between individuals belonging to different reference groups. There is however not yet any empirical evidence in this respect.

\section{REFERENCES}

Alesina, A., R. Di Tella, and R. MacCulloch, 2004. Inequality and happiness: Are Europeans and Americans different? Journal of Public Economics, 88, 2009-2042.

Alesina, A. and G-M. Angeletos, 2005. Corruption, inequality, and fairness. Journal of Monetary Economics 52(7): I227-I 244.

Alesina, A. and P. Giuliano, 20II. Preferences for redistribution. In (eds.) J. Benhabib, A. Bisin and M. O. Jackson, Handbook of Social Economics. Chapter 3. New York: Elsevier.

Algan, Y., P. Cahuc and M. Sangnier, 20II. Efficient and inefficient welfare states, IZA DP 5445.

Angrist, J.D. and J-S. Pischke, 2009. Mostly Harmless Econometrics: An Empiricist's Companion. Princeton, NJ, Princeton University Press.

Bénabou, R., and E.A. Ok, 200I. Social mobility and the demand for redistribution: the poum hypothesis. The Quarterly Journal of Economics, II6, 447-487.

Bergstrom, C. T. and M. Lachmann, 1998. Signaling among relatives. III. Talk is cheap. Procedures of the National Academy of Sciences. USA 95: 5100-5105.

Blanchflower, D. and A. Oswald, 2003. Does inequality reduce happiness? Evidence from the States of the USA from the 1970s to the 1990s. Unpublished manuscript.

Blanchflower, D. and A. Oswald, 2008. On the curvature of the reporting function from objective reality to subjective feelings, Economic Letters, 1000, 396-372.

Bowles S. and Y. Park, 2005. Emulation, inequality, and work hours: Was Thorsten Veblen right. Economic Journal, II5: F397-F4I2.

Cameron, C. and D.L. Miller, 20I0. Robust Inference with Clustered Data, Working Papers 107, University of California, Davis, Department of Economics.

Clark, A., 2003. Inequality-aversion and income mobility: A direct test. Delta Working paper 2003-II. 
Clark, A., 200I. What really matters in a job? Hedonic measurement using quit data, Labour Economics, 8, 223-242.

Clark, A., P. Frijters, and M.A. Shields, 2008. A survey of the income happiness gradient, Journal of Economic Literature, 46, 95-144.

Cruces, G., R. Perez Truglia, and M. Tetaz, 2013. Biased perceptions of income distribution and preferences for redistribution: evidence from a survey experiment. Journal of Public Economics, 98, 100-II 2.

Dawes, C.T., J.H. Fowler, T. Johnson, R. McElreath, and O. Smirnov, 2007. Egalitarian motives in humans. Nature. 446, 794-796.

Di Tella, R. and R. MacCulloch, 2009. Why Doesn't Capitalism Flow to Poor Countries? Comments and Discussion. Brookings Papers in Economic Activity, 285321.

Diener and Lucas, 1999. Personality and subjective well-being", in D. Kahneman, E. Diener, and N. Schwarz (eds.). Well-Being: The Foundations of Hedonic Psychology. Russell Sage Foundation, New York. Chapter II.

Fehr, E. and K.M. Schmidt, 1999. A theory of fairness, competition, and cooperation. Quarterly Journal of Economics, I14: 817-868.

Ferrer-i-Carbonell, A. and P. Frijters, 2004. How important is methodology for the estimates of the determinants of happiness?, The Economic Journal, I|4, 64I-659.

Ferrer-i-Carbonell, A., 2005. Income and well-being: An empirical analysis of the comparison income effect, Journal of Public Economics, 89, 997-1019.

Ferrer-i-Carbonell, A. and X. Ramos, 2009. Inequality aversion and risk attitudes. IZA Discussion Paper No.4703.

Ferrer-i-Carbonell, A., 20I I. Happiness Economics. Els Opuscles del CREI, vol. 28, May 2011 .

Ferrer-i-Carbonell, A., 2012. Happiness Economics. SERIEs, Journal of the Spanish Economic Association, 4: 35-60.

Frank, R.H., 2013. Are Positional Externalities Different? Journal of Public Economics, forthcoming.

Frey, B.S., M. Benz, and A. Stutzer, 2002. Happiness and Economics: How the Economy and Institutions Affect Human Well-Being. Princeton: Princeton University Press. 
Frey, B.S., M. Benz, and A. Stutzer, 2004. Introducing procedural utility: not only what but also how matters. Journal of Institutional and Theoretical Economics. 160, 377401 .

Frey, B. and L. Stutzer, 2002. Happiness and Economics: How Economy and Institutions Affect Human Well-Being, Princeton, NJ, Princeton University Press.

Giuliano, L. and A. Spilimbergo, 2009. Growing up in a recession: Beliefs and the macroeconomy, NBER working paper I532I.

Graham, C. and A. Felton, 2005. Does inequality matter to individual welfare: an exploration based on happiness surveys in Latin America. Center on Social and Economic Dynamics Working Papers Series No. 38, The Brookings Institution.

Grosfeld, I. and C. Senik, 20I0. The emerging aversion to inequality. Economics of Transition, 18: I-26.

Guven, C., C. Senik, and H. Stichnoth, 2010. You can't be happier than your wife. Happiness gaps and divorce, Journal of Economic Behavior \& Organization, 82(I), II0-130.

Hausman, J.A., 200I. Mismeasured variables in econometric analysis: problems from the right and problems from the left. The Journal of Economic Perspectives. 15: 5767.

Hirschman, A.O. and M. Rothschild, 1973. The changing tolerance for income inequality in the course of economic development; with a mathematical appendix, The Quarterly Journal of Economics, 87(4), 544-66.

Hopkins, E., 2008. Inequality, happiness and relative concerns: What actually is their relationship? Journal of Economic Inequality, 6: 35I-372.

Kahneman, D., 1999. Objective happiness, in D. Kahneman, E. Diener and N. Schwarz (eds.). Foundations of Hedonic Psychology: Scientific Perspectives on Enjoyment and Suffering. Russell Sage Foundation, New York. Chapter I.

Layard, R., 2010. Measuring subjective well-being, Science, 29, 534-535.

Luttmer, E., 2005. Neighbors as negatives: Relative earnings and well-being. Quarterly Journal of Economics, 120, 963-1002.

Morawetz, D., E. Atia, G. Bin-Nun, L. Felous, Y. Gariplerden, E. Harris, S. Soustiel, G. Tombros, and Y. Zarfaty, 1977. Income distribution and self-rated happiness: Some empirical evidence. The Economic Journal, 87, 51 I-522. 
Piketty, T. 1995, Social Mobility and Redistributive Politics. The Quarterly Journal of Economics, II0, 55I-84.

Powdthavee, N., 201I. The happiness Equation: The surprising economics of our most valuable asset. Icon Books UK \& Totem Books, US.

Sanfey, P and U. Teksoz, 2007. Does transition make you happy? The Economics of Transition. 15, 707-731.

Sandvik, E., E. Diener and L. Seidlitz, 1993. Subjective well-being: The convergence and stability of self-report and non-self-report measures, Journal of Personality, 6I, 3I7342.

Schwarze, J. and M. Harpfer, 2007. Are people inequality averse, and do they prefer redistribution by the state? Evidence from German longitudinal data on life satisfaction. Journal of Socio-Economics, 36, 233-249.

Senik, C., 2009. Income Distribution and Subjective Happiness: A Survey. OECD Social, Employment and Migration Working Papers, No. 96.

Steptoe, A. and J. Wardle, 2005. Positive affect and biological function in everyday life", Neurobiology of Aging. Suppl I, 108-12.

Tomes, N., 1986. Income distribution, happiness and satisfaction: A direct test of the interdependent preferences model. Journal of Economic Psychology, 7: 425-446.

Urry H. L., J. B. Nitschke, I. Dolski, D. C. Jackson, K. M. Dalton, C. J. Mueller, M. A. Rosenkranz, C. D. Ryff, B. H. Singer, and R. J. Davidson, 2004. "Making a life worth living: Neural correlates of well-being”, Psychological Science, 15, 367-72.

Van Praag, B.M.S., A. Hagenaars, and J. van Weeren, 1982. Poverty in Europe. Review of Income and Wealth, 28, 345-359.

Van Praag, B.M.S. and A. Ferrer-i-Carbonell, 2004. Happiness quantified: A satisfaction calculus approach. Oxford University Press. Oxford: UK.

Wooldrige, J. 2006. Econometric Analysis of Cross Section and Panel Data. Cambridge, MA: MIT Press.

\section{Acknowledgements}

We would like to thank Abigail Mcknight and participants at the London GINI meeting for helpful comments. Ada Ferrer-i-Carbonell acknowledges financial support from project ECO20II-29874-C02 (Ministerio de Ciencia e Innovación). Xavier Ramos 
acknowledges financial support from projects ECO20I0-21668-C03-02 (Ministerio de Ciencia e Innovación), 2009SGR-307 and XREPP (Direcció General de Recerca).

1 See Alesina and Giuliano (20II) for an excellent review of the literature on preferences for redistribution.

${ }^{2}$ The estimated coefficients evaluated in terms of trade-offs between variables are very similar and so is their statistical significance.

${ }^{3}$ These should of course be shocks that change the position of individuals in the distribution without changing (much) the structure of the distribution.

${ }^{4}$ We are not aware of any study that systematically examines the extent and origins of individual's misperceptions about income inequality. However, in a related study, Cruces, Pérez Tuglia and Tetaz (2013) examine misperceptions in own ranking in the income distribution and conclude that misperceptions about own position in the income distribution are systematic and are related to the position individuals have in their reference group. 